\title{
PENGUJIAN KEKERASAN DAN PENGAMATAN FOTO MAKRO AUTOMATIC SURFACE TREATMENT REL DENGAN VARIASI JARAK TORCH PEMANAS DAN NOZZLE PENDINGIN
}

\author{
Hari Boedi Wahjono ${ }^{1}$, hariboedi @ppi.ac.id \\ Adinda Cahya Permana ${ }^{2}$, adindacahya46@gmail.com
}

Teknologi Mekanika Perkeretaapian, Politeknik Perkeretaapian Indonesia Madiun, Indonesia

\begin{abstract}
Abstrak
Prototype automatic surface treatment yang spesifikasi di antaranya menggunakan seperangkat las oksi-asetilen, dengan penggerak motor DC $12 \mathrm{~V} / 24 \mathrm{~V}$, suplai daya accu $12 \mathrm{~V}$, serta pompa air $12 \mathrm{~V}$ masih belum memiliki data teknis tentang peningkatan kekerasan yang dihasilkan. Penelitian ini bertujuan untuk mengkomparasi perhitungan nilai kekerasan rel R.54 antara raw material dengan material yang mengalami automatic surface treatment. Pada penelitian ini metode pengujian yang digunakan adalah metode pengujian Brinell. Pada penelitian ini, dilakukan variasi jarak antara pemanas dengan pendingin dengan jarak $100 \mathrm{~mm}, 130 \mathrm{~mm}$, dan $160 \mathrm{~mm}$. Hasil dari pengujian yang telah dilakukan, variasi dengan jarak 160mm mengakibatkan kenaikan nilai kekerasan paling tinggi. Meningkat sebesar 8,9355 BHN, sedangkan pada variasi $130 \mathrm{~mm}$ sedikit lebih rendah yaitu 8,2581 BHN, serta pada variasi $100 \mathrm{~mm}$ nilai kekerasannya hanya meningkat sebesar 6,9892 BHN. Dengan hal ini maka lifetime dari rel juga akan meningkat, diasumsikan dengan perhitungan umur rel pada lintas Politeknik Perkeretaapian Indonesia surface treatment dapat meningkatkan umur rel.
\end{abstract}

Kata Kunci: Automatic Surface Treatment, Jarak, Kekerasan, Umur Rel.

\section{Abstract}

The prototype automatic surface treatment whose specifications include using an oxy-acetylene welding kit, with a $12 \mathrm{~V} / 24 \mathrm{~V}$ DC motor, $12 \mathrm{~V}$ battery supply, and a $12 \mathrm{~V}$ water pump still does not have technical data on the increase in hardness produced. This study aims to compare the calculation of the value of the R.54 rail hardness between raw materials and materials that undergo automatic surface treatment. In this study, the testing method used is the Brinell test method. In this study, variations of the distance between the heater and cooler were carried out with a distance of $100 \mathrm{~mm}, 130 \mathrm{~mm}$, and $160 \mathrm{~mm}$. The results of the tests that have been carried out, variations with a distance of $160 \mathrm{~mm}$ resulted in the highest increase in hardness values. It increased by $8.9355 \mathrm{BHN}$, while in the 130mm variation it was slightly lower at $8.2581 \mathrm{BHN}$, and in the $100 \mathrm{~mm}$ variation the hardness value only increased by $6.9892 \mathrm{BHN}$. With this, the lifetime of the rail will also increase, it is assumed that by calculating the age of the rail on the Indonesian Railway Polytechnic cross, surface treatment can increase the life of the rail.

Keywords: Automatic Surface Treatment, Distance, Hardness, Rail Life.

\section{Pendahuluan}

Semakin bertambah populasi penduduk dibutuhkan transportasi yang memadai, salah satunya adalah transportasi kereta api. Guna mendapatkan pelayanan kereta api yang memadai baik angkutan penumpang maupun pengiriman baranag, maka dibutuhkan kegiatan yang dinamakan perawatan sarana perkeretaapian. Perawatan sarana perkertaapian terdiri dari timebased atau berdasarkan waktu dan perawatan sarana berdasarkan kilometers based atau berdasarkan jarak tempuh.

Menurut Undang - Undang Nomor 23 Tahun 2007, jalan rel adalah satu kesatuan konstruksi yang terbuat dari baja, beton, atau konstruksi lain yang terletak di permukaan, di bawah, dan di atas tanah atau bergantung beserta perangkatnya yang mengarahkan jalannya kereta api. Batang rel merupakan komponen utama pada jalan rel yang terdiri dari struktur balok menerus dan terletak di atas tumpuan bantalan serta berfungsi untuk menuntun dan mengarahkan pergerakan roda kereta api, selain itu rel juga berkemampuan untuk menyalurkan serta menerima beban secara langsung dari roda kereta api ke bantalan tanpa menimbulkan kerusakan. Permukaan atau kepala rel kereta api memiliki persyaratan kekerasan tidak boleh kurang dari 320 BHN (Peraturan Menteri Nomor 60 Tahun 2012).

Dalam pembangunannya rel kereta perlu dibangun dengan kokoh dikarenakan akan dilintasi oleh kereta berulang kali dengan beban yang berat. Maka dari itu, pembangunan rel harus dilakukan 
dengan kokoh agar mampu menahan beban kereta yang berjalan melintasi rel dalam waktu yang lama. Kereta api membutuhkan jalan rel yang aman dan kuat untuk dinas sebuah sarana perkeretaapian, dan jalan rel tersebut memerlukan perawatan yang efisien serta dapat meningkatkan kualitas jalan rel tersebut.

Saat pada daerah lengkungan, tanjakan serta sambungan batang rel, gesekan yang ditimbulkan sangat besar. Gesekan itu akan membuat temperatur rel menjadi sangat tinggi (panas), sehingga mengakibatkan perubahan fisis material. Perubahan fisis material dapat menimbulkan adanya keausan dan patah pada rel. Agar menghindari keausan berlanjut maka nilai kekerasan rel harus lebih besar daripada kekerasan roda kereta (Surawan, 2019). Kekerasan sendiri adalah kemampuan suatu material dalam menahan indentasi dari material lain yang lebih keras (Sari, 2018).

Permasalahan yang terdapat pada rel kereta api menjadi penyebab industri perkeretaapian berlomba-lomba mencari solusi untuk mengatasi permasalahan tersebut. Beberapa jenis permasalahan yang sering ditemui yaitu keretakan pada rel, rel keriting, pengelupasan permukaan rel, dan keausan. Berbagai jenis permasalahan tersebut, apabila tidak diperhatikan secara serius maka dapat menimbulkan dampak yaitu berkurangnya aspek kenyamanan dan keselamatan transportasi kereta api. Permasalahan berupa kerusakan pada rel terjadi karena kereta dengan beban yang berlebihan melintasi rel yang tidak sesuai spesifikasinya, faktor lingkungan yang kurang ideal, jalur lintas yang padat, serta kualitas dari proses manufaktur rel kereta api (Wirawan et. al.,., 2020)

Tindakan preventif perlu dilakukan untuk mencegah terjadinya kerusakan pada rel tersebut (Prihastono, 2017). Salah satu tindakan preventif yang dilakukan untuk meningkatkan kekerasan rel yaitu flame hardening, dimana metode ini telah banyak digunakan (Haqi, 2006). Metode flame hardening dapat diimplementasikan dikarenakan yang terkena gesekan hanya bagian luar atau permukaannya saja.

Saat ini ada beberapa peneliti yang telah mengembangkan alat yang digunakan untuk meningkatkan sifat mekanik permukaan rel sehingga diharapkan dapat mengatasi permasalahan di atas. Automatic surface treatment adalah salah satu contoh alat yang dikembangkan. Keunggulan alat ini salah satunya dapat berjalan secara otomatis dengan menggunakan proses flame hardening sehingga dapat meningkatkan kekerasan permukaan rel kereta sehingga lebih efisien (Wirawan et al., 2020).
Flame hardening dapat meningkatkan kekerasan permukaan rel kereta api dengan cara menggunakan nyala api pada temperatur kritis dalam selang waktu tertentu kemudian didinginkan dengan cepat (quenching) menggunakan media air sehingga mendapatkan kekerasan yang baik. Dengan dilakukannya pengujian kekerasan, maka akan didapatkan nilai kekerasan dari suatu benda. Selain itu berbagai metode pengujian kekerasan terstandar yang dilakukan guna menguji kekerasan logam salah satunya adalah pengujian Brinell. Pengujian Brinell dilakukan guna menentukan kekerasan material dalam bentuk daya tahan terhadap indentor yang ditekankan pada permukaan (Sari, 2018). Untuk mengetahui hasil yang paling optimal, perlu dilakukan beberapa eksperimen untuk pembanding manakah variasi yang dapat menghasilkan nilai kekerasan rel paling tinggi dengan proses flame hardening tersebut.

Penelitian Willy dkk (2020) yang berjudul desain prototype teknologi automatic surface treatment untuk meningkatkan ketahanan jalan rel kereta api meneliti pengaruh surface treatment terhadap nilai kekerasan terhadap struktur mikro rel UIC R42. Proses surface treatment dilakukan dengan tujuan guna meningkatkan kekerasan pada permukaan rel kereta api untuk meminimalisir keausan. Surface treatment diaplikasikan menggunakan metode flame hardening menggunakan panas gas oksi-asetilen dengan variasi nyala api yaitu netral, karburasi dan oksidasi pada holding time selama 30 menit dengan media pendingin berupa air. Hasil penelitian Boedi mengungkapkan bahwa proses surface treatment memberikan pengaruh peningkatan kekerasan pada rel kereta api UIC R42 tertinggi sebesar 235 VHC dengan struktur mikro yang dihasilkan yaitu cenderung membentuk struktur mikro martensit.

Penelitian Dwiwandono (2017), yang berjudul metalurgi analisa strukturmikro dan pengaruhnya terhadap sifat mekanis batangan rel tipe R54 meneliti tentang Mikro struktur baja R54 di Jerman (Steel Rail G) dan Cina (Steel Rail C) dan pengaruhnya terhadap sifat mekanik. Dari penelitian tersebut dihasilkan bahwa kedua tipe batangan tersebut struktur mikronya adalah ferit dan perlit. Kedua tipe rel tersebut tergolong baja kandungan $\mathrm{C}$ tinggi yaitu $0,7 \%$ berat, serta unsur pemadunya sama yaitu $\mathrm{MN}$, sebesar $1 \%$ berat. Hasil dari kekuatan tarik, kekuatan luluh serta elongasi tidak ada perbedaannya. Tetapi pada kekerasannya terlihat nilai kekerasan Steel Rail G lebih besar daripada Steel Rail C, dikarenakan ada perbedaan unsur pemadu serta jarak lamela dari fasa perlit dari kedua jenis rel tersebut. 
Penelitian Apriyanto (2011) yang berjudul pengaruh jarak torch pemanas dengan nozzle pendingin terhadap kekerasan permukaan baja karbon medium pada proses flame hardening meneliti pada proses flame hardening jarak torch pemanas dengan nozzle pendingin berpengaruh terhadap nilai kekerasan serta kedalaman pengerasannya. Proses ini menggunakan nyala api karburasi dengan variasi jarak torch pemanas dengan nozzle pendinginnya adalah $60 \mathrm{~mm}, 40 \mathrm{~mm}$, dan $20 \mathrm{~mm}$. Hasil yang didapatkan adalah semakin lebar atau jauh jaraknya maka kedalaman pengerasannya akan semakin dalam.

Penelitian Nugroho (2009) yang berjudul pengaruh kecepatan torch dan jenis nyala api terhadap kekerasan permukaan baja karbon pada proses automatic flame surface hardening meneliti pada proses flame hardening yang menggunakan variasi kecepatan torch dan jenis nyalanya akan berpengaruh pada kekerasan baja karbon. Penelitian ini menggunakan variasi kecepatan $28 \mathrm{~mm} /$ menit menggunakan nyala api karburasi, sehingga kekerasan spesimen menjadi 879,10 HV dan 232,80 HV pada bagian atas dan bawah spesimen, hasil tersebut adalah hasil yang paling optimal.

Penelitian Nurkhozin (2006) yang berjudul pengaruh manual flame hardening pada baja tempa mempelajari pengaruh proses flame hardening pada baja tempa. Melalui uji kekerasan, dikombinasikan dengan perlakuan penempaan dan annealing, dapat diperoleh nilai kekerasan tertinggi (yaitu 865,8 HVN). Pada pengamatan mikrostruktur, terbentuk struktur martensit dan ferit pada sampel setelah penempaan, annealing dan flame hardening.

Penelitain Lee dkk (2003) yang berjudul effects of the surface temperature and cooling rate on the residual stresses in a flame hardening of $12 \mathrm{cr}$ steel yang membahas tentang studi eksperimen dengan menggunakan proses flame hardening untuk mengatur kekerasan permukaan serta kedalaman pengerasan dari baja $12 \mathrm{Cr}$. Dalam penelitian ini, perubahan suhu dikontrol dengan tepat guna mengetahui pengaruh suhu permukaan dan kecepatan quenching. Dengan hasil yang didapat dari penelitian ini bahwa kekerasan baja $12 \mathrm{Cr}$ meningkat dari $250 \mathrm{HV}$ menjadi $420-550 \mathrm{HV}$ menunjukkan bahwa flame hardening dapat meningkatkan kekerasan. Semakin cepat pendinginan, semakin dalam material akan mengeras.

\section{Metode}

Penulis membutuhkan data-data untuk menyusun tugas akhir ini baik dari observasi langsung dan studi literatur. Observasi dilakukan dengan melaksanakan langsung surface treatment dari tahap persiapan hingga pengujian serta pengamatan. Studi literatur dilakukan dengan melihat pada penelitian dan buku-buku sebagai pelengkap dari kajian teoritis.

\section{Diagram Alir Penelitian}

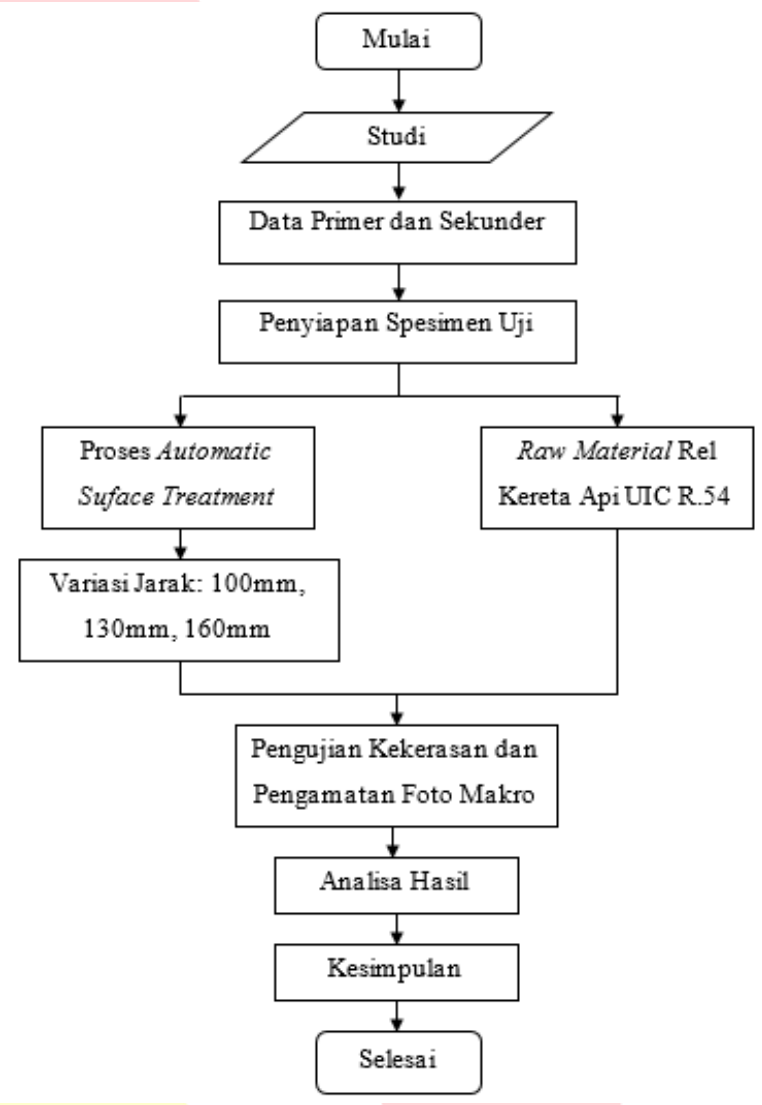

Gambar 1. Diagram Alir Penelitian

\section{Alat Uji}

Peralatan yang digunakan dalam pengambilan data pada penelitian diantaranya:

a. Prototype surface treatment adalah salah satu alat yang dikembangkan oleh suatu kelompok taruna dengan bantuan dosen pembimbingnya. Alat ini berfungsi untuk meningkatkan nilai kekerasan rel dengan menggunakan sistem flame hardening.

b. Alat ukur panjang yang digunakan adalah mistar Dalam penelitian ini, mistar berfungsi untuk mengukur jarak antara nozzle pendingin dengan torch pemanas guna menyesuaikan dengan variable yang telah ditentukan.

c. Alat uji kekerasan yang digunakan adalah NDT Portable Hardness Test dengan merek Proceq Equotip Piccolo Bambino 2. Prosedur 
pengukuran mengacu pada standar ASTM A956, ASTM E140, dan ASTM A370. ASTM A956 mengatur tentang standar metode uji untuk pengujian kekerasan produk baja. ASTM E140 mengatur tentang standar tabel konversi kekerasan untuk logam. Sedangkan ASTM A370 mengatur tentang standar metode pengujian mekanik produk baja.

\section{Analisis Data}

Dengan data yang telah diperoleh dapat dianalisis dengan membandingkan nilai kekerasan antara sebelum dilakukan perlakuan dengan sesudah dilakukan perlakuan maupun perbedaan antar variasinya. Setelah dilakukan automatic surface treatment beserta pengukuran nilai kekerasan, dapat dilakukan perhitungan umur jalan rel untuk membuktikan pengaruh dari proses automatic surface treatment tersebut. Selain itu, akan terlihat perbedaan hasil dari foto makro material dari data tersebut, sehingga nantinya dapat ditarik kesimpulan, variasi manakah yang lebih optimal untuk dilakukan. Namun sebelum itu terdapat beberapa tahap, yakni tahap persiapan dan tahap pengujian yang masing-masing memiliki 2 tahapan, secara berurutan yaitu:

a. Membersihkan karat yang ada pada kepala rel dengan menggunakan amplas.

b. Melakukan proses flame hardening

c. Pengujian Kekerasan Brinell

d. Pengamatan Foto Makro

\section{Pembahasan}

Bahan yang digunakan untuk penelitian ini adalah rel baja jenis UIC-R.54 yang merupakan baja karbon tinggi. Sebelum melakukan penelitian, tahapan awal yang dilakukan yaitu mempersiapkan permukaan spesimen rel yang akan diuji kekerasannya serta dianalisis struktur makro permukaannya. Lakukan pengamplasan pada permukaan spesimen sehingga tidak ada benda asing yang menempel pada permukaan spesimen. Setelah dilakukan pengamplasan dilanjutkan dengan pemolesan dengan menggunakan autosol lalu dilap dengan kain dan larutan thinner.

Jarak $100 \mathrm{~mm}$ diambil dari spesifikasi alat tersebut dimana jarak deafult terdekat antara torch pemanas dengan nozzle pendingin sebesar $100 \mathrm{~mm}$ dan jarak maksimal 370mm, maka panjang dari pengatur jarak torch pemanas dengan nozzle pendingin tersebut yaitu 270mm (Wanaradi, 2020). Jarak $130 \mathrm{~mm}$ dan $160 \mathrm{~mm}$ digunakan sebagai beberapa sampel pengujian yang berfungsi untuk mengetahui selisih nilai kekerasan setiap $30 \mathrm{~mm}$.

pesimen pada penelitian ini dibuat dengan panjang $300 \mathrm{~mm}$ dan lebar $20 \mathrm{~mm}$ pada tiap-tiap spesimen uji. Hal ini dikarenakan mempertimbangkan dari perangkat uji yang digunakan serta kemampuan pada alat surface treatment. Setelah dilakukan penyiapan maka permukaan pada rel akan menjadi bersih dan halus tanpa ada karat yang menempel pada spesimen.

Pengambilan data yang dilakukan setelah penyiapan serta pengklasifikasian spesimen yaitu pengukuran nilai kekerasan. Pada penelitian ini terdapat dua tahap yaitu tahap pengukuran nilai kekerasan dan tahap pengolahan data nilai kekerasan. Data tersebut diolah dalam bentuk grafik agar memudahkan dalam membandingkan hasil pengukuran. Nilai pengukuran diolah dan dibuat rata-rata lalu dikonversikan menjadi grafik guna memudahkan dalam proses analisis data.

Spesimen 100, 130 dan 160 merupakan spesimen dengan variabel jarak torch pemanas dengan nozzle pendingin berjarak sesuai dengan angka yang dimasukkan yakni 100, 130 dan 160 . Spesimen ini berawal dari raw material yang telah dilakukan pembersihan dengan cara diamplas agar tidak merusak struktur permukaannya dan menghilangkan karat pada spesimen. Setelah dilakukan penyiapan pada permukaan spesimen, dilakukan pengujian kekerasan pada masingmasing area agar ditemukan nilai kekerasan sebelum dilakukan treatment dan terlihat perbedaannya dengan setelah dilaksanakan treatment.

Setelah menyelesaikan seluruh proses pengambilan serta pengolahan data tentang nilai kekerasan pada setiap spesimen uji. Langkah selanjutnya adalah melakukan analisis terhadap data yang telah diperoleh. Berdasarkan data dari pengujian kekerasan pada sub bab sebelumnya, dapat ditari kesimpulan bahwa nilai kekerasan ratarata RAW dari masing-masing spesimen uji memiliki nilai kekerasan jauh di bawah minimum dengan yang tertulis pada Peraturan Menteri Perhubungan Nomor 60 Tahun 2012 dimana nilai kekerasan permukaan rel tidak boleh kurang dari $320 \mathrm{BHN}$.

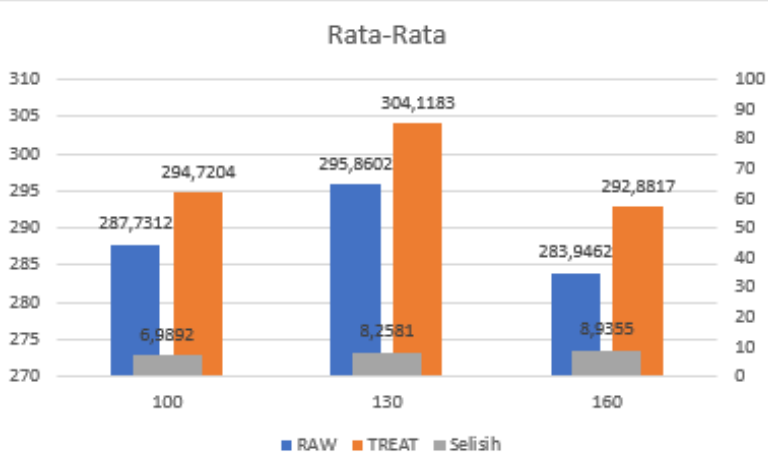

Gambar 2. Rata-Rata Setiap Spesimen Uji 
Dapat dilihat bahwa masing-masing perlakuan memiliki pengaruh pada nilai kekerasan. Pada spesimen RAW 100 nilai kekerasan tertinggi pada RAW 100/1 mencapai 294 BHN, pada RAW 100/2 mencapai 368 BHN, sedangkan pada RAW 100/3 mencapai 319 BHN. Hasil pengukuran nilai kekerasan pada spesimen TREAT 100 memiliki kekerasan tertinggi 379 BHN di salah satu titiknya, namun jika dihitung rata-rata nilai kekerasan pada TREAT 100/1 yaitu 284,935 BHN, pada TREAT 100/2 yaitu 315,226 BHN, pada TREAT 100/3 yaitu 284 BHN. Dapat dilihat bahwa nilai kekerasan rata-rata RAW sebesar 287,7312 BHN sedangkan spesimen TREAT nilai kekerasannya sebesar 294,7204 BHN, hal ini menunjukkan bawah dengan jarak antara torch pemanas dengan nozzle pendingin mengakibatkan nilai kekerasan rel UIC.R-54 mengalami kenaikan nilai kekerasan sebesar 6,9892 BHN.

Nilai kekerasan tertinggi pada RAW 130/1 mencapai 308 BHN, pada RAW 130/2 mencapai 363 BHN, pada RAW 130/3 mencapai 312 BHN, lalu jika dihitung rata-rata pada spesimen RAW 130. Hasil pengukuran nilai kekerasan pada spesimen TREAT 130 memiliki kekerasan tertinggi 363 BHN di salah satu titiknya, namun jika dihitung rata-rata nilai kekerasan pada TREAT 130/1 yaitu 286 BHN, pada TREAT 130/2 yaitu 316,323 BHN, pada TREAT $130 / 3$ yaitu 285,258 BHN. Spesimen 130 mengalami peningkatan nilai kekerasan sebesar 8,2581 BHN dimana saat belum dilaksanakan surface treatment (RAW) nilai kekerasannya sebesar 295,8602 BHN, sedangkan spesimen TREAT nilai kekerasan spesimen mencapai 304,1183 BHN.

Pada RAW 160/2 mencapai 339 BHN, pada RAW 160/3 mencapai 294 BHN, lalu jika dihitung rata-rata pada spesimen RAW 100 secara keseluruhan hanya mencapai 283,946 BHN. Hasil pengukuran nilai kekerasan pada spesimen TREAT 160 memiliki kekerasan tertinggi 421 BHN di salah satu titiknya, namun jika dihitung rata-rata nilai kekerasan pada TREAT 160/1 yaitu 283,839 BHN, pada TREAT $160 / 2$ yaitu 319,71 BHN, pada TREAT 160/3 yaitu 275,097 BHN. Spesimen 160 memiliki peningkatan kekerasan yang paling tinggi, dengan meningkatnya nilai kekerasan sebesar 8,9355 BHN. Sebelum dilakukan surface treatment (spesimen RAW) nilai kekerasannya sebesar 283,9462 BHN, lalu setelah dilakukan surface treatment (TREAT) nilai kekerasannya mencapai 292,8817 BHN.

Setelah seluruh tahapan pengukuran selesai dilakukan, dapat disimpulkan bahwa nilai kekerasan tertinggi dimiliki oleh spesimen jarak torch pemanas dengan nozzle pendingin $160 \mathrm{~mm}$.
Dapat dilihat bahwa selisih dari spesimen RAW dan TREAT sebesar 8,9355 BHN. Sedangkan pada spesimen 130 selisih antara spesimen RAW dan TREAT sedikit di bawah spesimen 160 yaitu 8,2581 BHN. Sedangkan spesimen 100 memiliki peningkatan nilai kekerasan paling kecil dapat dilihat selisih antara RAW dan TREAT spesimen ini hanya 6,9892 BHN. Maka dari itu dapat ditarik kesimpulan dari penelitian ini yaitu semakin jauh jarak antara torch pemanas dengan nozzle pendingin dengan kapasitas wajar, setidaknya dapat dilakukan proses quenching dalam beberapa detik, maka nilai kekerasannya semakin tinggi. Penelitian ini dibatasi dengan menggunakan rel bertipe R.54 dan dilakukan pada lintas PPI Madiun, karena jika tidak menggunakan rel bertipe R.54 dan pada lintas PPI Madiun mungkin hasil pengukurannya akan berbeda.

Tabel 1. Hasil Perhitungan Umur Rel

\begin{tabular}{|c|c|c|c|}
\hline JARAK & RAW & TREAT & SELISIH \\
\hline \multirow{2}{*}{100} & $\begin{array}{c}30,402 \\
\text { tahun }\end{array}$ & $\begin{array}{c}31,14 \\
\text { tahun }\end{array}$ & $\begin{array}{c}0,738 \\
\text { tahun }\end{array}$ \\
\hline \multirow{2}{*}{130} & $\begin{array}{c}30,402 \\
\text { tahun }\end{array}$ & $\begin{array}{c}32,009 \\
\text { tahun }\end{array}$ & $\begin{array}{c}1,607 \\
\text { tahun }\end{array}$ \\
\hline \multirow{2}{*}{160} & $\begin{array}{c}30,402 \\
\text { tahun }\end{array}$ & $\begin{array}{c}32,12 \\
\text { tahun }\end{array}$ & $\begin{array}{c}1,718 \\
\text { tahun }\end{array}$ \\
\hline
\end{tabular}

Jadi dapat ditarik kesimpulan bahwa variasi dengan jarak torch pemanas dengan nozzle pendingin $160 \mathrm{~mm}$ lebih optimal untuk digunakan. Hal ini dibuktikan oleh perhitungan bahwa variasi $160 \mathrm{~mm}$ memiliki penambahan umur sebanyak 1,718 tahun sedangkan variasi $130 \mathrm{~mm}$ memiliki penambahan umur 1,607 tahun, sedangkan variasi $100 \mathrm{~mm}$ memiliki penambahan umur 0,738 tahun. Menurut teori yang dikemukakan oleh Surawan (2019), hal ini dikarenakan naiknya nilai kekerasan permukaan rel sehingga nilai keausan permukaan rel menurun. Hal ini juga mengacu pada referensi hasil penelitian dari Nippon Steel Corp (2014), dimana dijelaskan bahwa semakin tinggi nilai kekerasan permukaan rel, maka nilai keausan juga semakin menurun sehingga usia layan rel mengalami peningkatan.

Spesimen yang digunakan adalah rel kereta api jenis R.54 dengan karbon 0,8\%. Dilakukan proses automatic surface treatment dengan daerah nyala api yang berbeda.

Tabel 2. Temperatur Nyala Api

\begin{tabular}{|c|c|c|}
\hline No. & Daerah Nyala Api & $\begin{array}{c}\text { Panas Diterima } \\
\left({ }^{\circ} \mathrm{C}\right)\end{array}$ \\
\hline 1 & Luar $\left(1275^{\circ} \mathrm{C}\right)$ & 235 \\
\hline 2 & Tengah $\left(2100^{\circ} \mathrm{C}\right)$ & 442 \\
\hline 3 & Dalam $\left(3500^{\circ} \mathrm{C}\right)$ & 759 \\
\hline
\end{tabular}

Panas yang diterima oleh spesimen adalah $235^{\circ} \mathrm{C}$ sehingga tidak ada perubahan fasa. Tetap 
pada daerah ferrite $(\alpha)+$ Fe3C. Kemudian pada suhu $442^{\circ} \mathrm{C}$ spesimen tersebut masih belum mengalami perubahan fasa. Pada suhu $759^{\circ} \mathrm{C}$ terjadi perubahan fasa dari satu fasa solid menjadi dua fasa solid yang berbeda yaitu austenite $(\gamma)$ ferrite $(\alpha)+\mathrm{Fe} 3 \mathrm{C}$, hal ini dikarenakan adanya reaksi eutektoid.

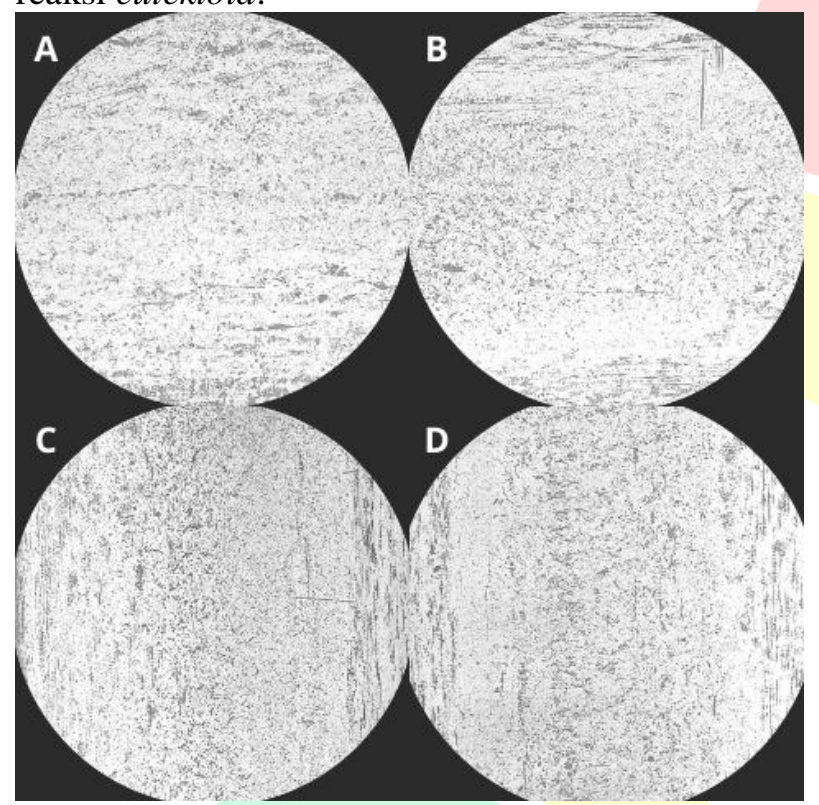

Gambar 3. Hasil Foto Makro

Foto "A" merupakan hasil foto makro dari spesimen RAW, pada spesimen RAW terlihat masih banyak permukaan kasar dan terdapat banyak cekungan hitam yang tidak dapat dihilangkan saat proses penyiapan spesimen uji. Pada foto "B" merupakan hasil foto makro dari spesimen TREAT 100, ditunjukkan bahwa mengalami pengurangan cekungan hitam. Hal ini disebabkan adanya reaksi metalurgi yang terjadi dalam proses pemanasan dan pendinginan. Reaksi yang terjadi pada spesimen foto B merupakan reaksi pemisahan. Reaksi ini berupa perubahan struktur material yang terjadi akibat adanya penyisipan unsur karbon pada proses flame hardening (Callister, W.D, 2007). Hal ini dibuktikan dengan adanya perubahan tekstur yang sebelumnya kasar kemudian berubah menjadi sedikit lebih halus dari foto $\mathrm{A}$.

Foto "C" merupakan hasil foto makro spesimen TREAT 130, ditunjukkan bahwa spesimen TREAT 130 mengalami pengurangan cekungan hitam. Hal ini juga dikarenakan adanya reaksi pemisahan. Sehingga cekungan hitam tersebut menjadi lebih sedikit serta permukaannya juga lebih halus dari pada foto B. Foto " $D$ " merupakan hasil foto makro spesimen TREAT 160, ditunjukkan bahwa spesimen TREAT 160 mengalami lebih banyak pengurangan cekungan hitam. Hal ini juga dikarenakan reaksi metalurgi pemisahan. Sehingga permukaan yang dihasilkan lebih halus dari pada permukaan pada foto "A", "B", maupun "C".

Tahapan penelitian selanjutnya yaitu melakukan identifikasi permukaan setiap spesimen, baik spesimen RAW maupun spesimen TREAT. Di bawah ini disajikan gambar 4.16 yang merupakan identifikasi kondisi permukaan spesimen RAW, spesimen TREAT 100, spesimen TREAT 130 dan spesimen TREAT 160 menggunakan software Image J

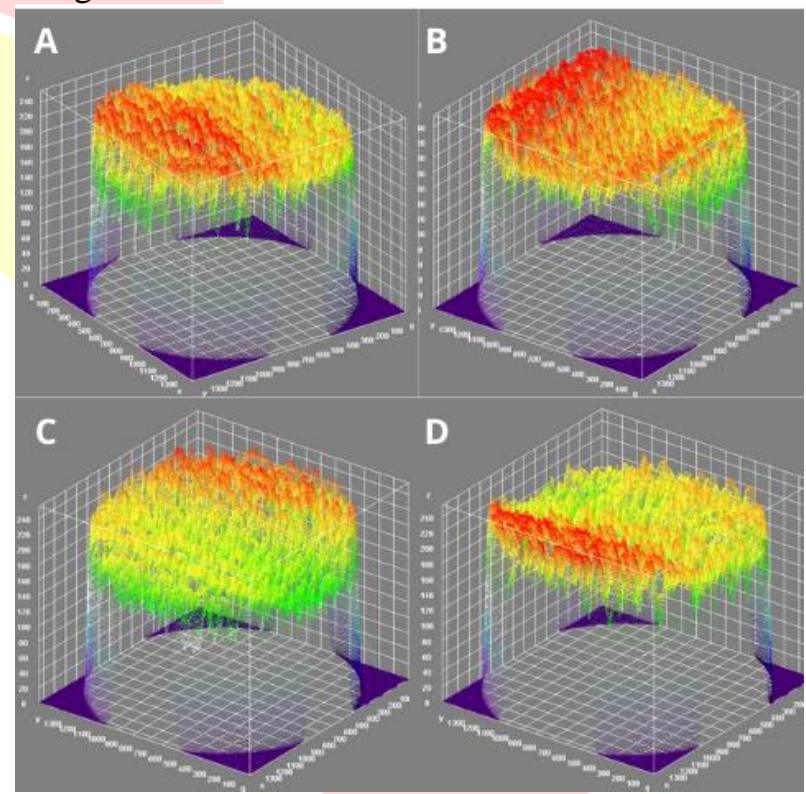

Gambar 4. Hasil Pengolahan dengan ImageJ

Setelah menentukan parameter dalam penelitian, dapat diamati pada gambar 4.16 bahwa pada foto "A" dimana foto A merupakan spesimen RAW didominasi dengan spektrum warna merah merata dengan sedikit bintik-bintik kuning. Berdasarkan skala spektrum, spektrum tertinggi yang dihasilkan berada pada rentang 220 hingga 240. Foto "B" merupakan hasil dari spesimen TREAT 100 yang didominasi dengan warna merah dan merata ke seluruh permukaan. Hal ini mungkin saja dikarenakan pemanasan yang merata. Maka spektrum yang dihasilkan berada pada rentang 220 240.

Foto "C" merupakan hasil dari spesimen TREAT 130 yang didominasi dengan warna merah dengan paduan sedikit jingga. Selain itu, pada daerah tertentu juga didominasi dengan warna jingga. Perubahan dominasi spektrum warna tersebut terjadi karena besarnya masukan panas yang bergantung pada jarak torch pemanas dengan nozzle pendingin sehingga menimbulkan dampak pada luasan yang terpengaruh oleh panas. Foto "D" merupakan hasil dari spesimen TREAT 160 yang sebagian didominasi dengan warna merah, dan sebagian lainnya didominasi dengan warna jingga. 
Perubahan dominasi ini juga disebabkan oleh besarnya masukan panas yang diakibatkan oleh jarak torch pemanas dengan nozzle pendingin sehingga berpengaruh pada luasan yang terpengaruh oleh panas.

\section{Kesimpulan}

Hasil pengukuran nilai kekerasan rata-rata pada spesimen RAW 100 sebesar 287,7312 BHN lalu setelah dilakukan proses surface treatment dengan variasi TREAT 100 sehingga nilai kekerasannya meningkat sebesar 6,9892 BHN sehingga menjadi 294,7204 BHN. Lalu pada spesimen RAW 130 nilai kekerasannya sebesar 295,8602 BHN dan setelah dilakukan proses surface treatment dengan variasi TREAT 130 nilai kekerasannya meningkat sebesar 8,2581 BHN sehingga nilai kekerasannya menjadi 304,1183 BHN. Terakhir pada spesimen RAW 160, nilai kekerasan rata-ratanya sebesar 283,9462 BHN lalu dengan dilakukan surface treatment dengan variasi TREAT 160, nilai kekerasannya meningkat sebesar 8,9355 BHN sehingga nilai kekerasannya menjadi 292,8817 BHN. Spesimen RAW merupakan spesimen tanpa perlakuan, sehingga nilai kekerasan rata-ratanya lebih rendah daripada spesimen TREAT. Kemudian dari masing-masing perlakuan mengalami peningkatan. Peningkatan nilai kekerasan terbesar dialami oleh variasi TREAT 160 dibandingkan dengan variasi TREAT 130 dan TREAT 100.

Perlakuan automatic surface treatment dapat menambah umur jalan rel. Pada raw material umur rel tersebut mencapai 10.945 hari. Lalu setelah mengalami proses automatic surface treatment, umur jalan rel mengalami peningkatan. Penambahan terbesar dialami oleh perlakuan TREAT 160 menambah umur rel sebesar 618 hari. Sedangkan pada TREAT 130 mengalami penambahan umur rel sebesar 578 hari. Lalu peningkatan terendah dialami oleh TREAT 100 dengan penambahan umur rel sebesar 265 hari.

Perlakuan surface treatment yang diberikan ke spesimen penelitian ini menimbulkan perubahan tekstur apabila diamati menggunakan foto makro. Terlihat pada saat pemrosesan menggunakan software ImageJ, pada spesimen RAW memiliki permukaan yang kasar, tetapi dengan dilakukan automatic surface treatment permukaan tersebut terlihat lebih halus.

\section{Referensi}

Adi, W. T. (2019). Kajian Umur Jalan Rel Berdasarkan Keausan dengan Metode dari AREA dan Perjana. Jurnal Perkeretaapian
Indonesia,

$3(2)$.

https://doi.org/10.37367/jpi.v3i2.84

Ambiyar, \& Putra, Z. A. (2007). Pengaruh Temperatur ICA dan Temper Terhadap Baja Karbon Sedang. Laporan Penelitian. Universitas Negeri Padang.

Apriyanto, M. (2011). Pengaruh Jarak Torch Pemanas Dengan Nozzle Pendingin Terhadap Kekerasan Permukaan Baja Karbon Medium Pada Proses Flame Hardening.

Clark D. S. Varney W. R. (1962). Physical Metallurgy For Engineering. D. Van Nostrand Company, INC.

Collins, Tony J., "ImageJ for Microscopy." BioTechnique, Vol. 43 (July, 2007): S25-S30. https://doi.org/10.2144/000112517

Dieter G. E. (1996). Metalurgi Mekanik. Ahli Bahasa: Sriati Djaprie. Eelangga. Jakarta.

Dwiwandono, R., Firmansyah, L., Herbirowo, S., Hasbi, Y., \& Citrawati, F. (2017). Metalurgi Analisa Strukturmikro Dan Pengaruhnya Terhadap Sifat Mekanis Batangan Rel Tipe R54. Metalurgi, 2, 67-76.

Erich Folkhard. (1984). Welding Metalurgy of Stainless Stee. Spring-Verlig Wien. New York.

Febriansyah, A. (2017). Tinjauan Atas Proses Penyusunan Laporan Keuangan Pada Young Enterpreneur Academy Indonesia Bandung. Jurnal Riset Akuntansi, 8(2). https://doi.org/10.34010/jra.v8i2.525

Fretz. Buergler. (1978). Teknik Bengkel Volume 5. Institut Teknologi Bandung. Indonesia

Hari Boedi, Willy Artha Wirawan, Fadli Rozaq, Dadang Sanjaya Atmaja. (2020). The Effect Of Quenching Media On Surface Treatment Process On The Rel UIC R42 (Union Internasionale Des Chemins De Fer-42) Endurance. International Journal of Advanced Science and Technology, 29(6s), $1329-1336$

JFE Steel Corporation. Rail Profiles. Diakses pada 15 Februari 2021, dari https://www.jfe- 
steel.co.jp/en/products/shapes/catalog/d1e001.pdf

Kementerian Perhubungan. (2012). Persyaratan Teknis Jalur Kereta Api. PM. 60 Tahun 2012, $1-57$.

Lee, M. K., Kim, G. H., Kim, K. H., \& Kim, W. W. (2006). Effects of the surface temperature and cooling rate on the residual stresses in a flame hardening of $12 \mathrm{Cr}$ steel. Journal of Materials Processing Technology, 176(1-3), 140-145.

Mahendra, T. S. S. I. (2020). Pembuatan Prototype Surface Treatment Untuk Meningkatkan Ketahanan Permukaan Rel Kereta Api. [Tugas Akhir]

Martin F. Ilja K. Michael K. Roland G. Wolfam V. (2017). Reduction of Burr Formation for Conventional Shear Cutting Of Boron-Alloyed Sheets Though Focused Heat Treatment. Thecnische Universitat Miinchen. Intitute of Metal Forming and Casting. Germany.

Muh Nurkhozin. (2006). Pengaruh Mnual Flame Hardening Pada Baja Tempa. Tugas Akhir Jurusan Teknik Mesin. Surakarta : Universitas Sebelas Maret.

Nippon Steel \& Sumitomo Metal. (2014). Rails. Tokyo: Nippon Steel \& Sumitomo Metal Corporation.

Nugroho, A. S., Haryadi, G. D., Hardjuno, A. T., Jurusan, M., Mesin, T., Teknik, F., Diponegoro, U., Jurusan, D., Mesin, T., Teknik, F., \& Diponegoro, U. (2014). Pengaruh Proses Normalizing Terhadap Nilai Kekerasan. 2(3), 249-257.

Nugroho, D. S. (2009). Pengaruh Kecepatan Torch Dan Jenis Nyala Api Terhadap Kekerasan Permukaan Baja Karbon Pada Proses Automatic Flame Surface Hardening. [Skripsi].

Prihastono, E., \& Prakoso, B. (2017) Perawatan Preventif untuk mempertahankan utilitas performace pada mesin cooling tower di CV. Arhu Tapselindo Bandung. Dinamika Teknik, X, 17-27.
Rezki, F. (2015). Pengaruh Carburizing Pada Sproket Terhadap Kekerasan Material dan Ketahanan Aus. Jurusan Teknik Mesin Universitas Lambung Mangkurat. Banjarmasin.

Sari, H. S. (2018). Material Teknik. Yogyakarta: Deepublish.

Schonmetz A. In. Gruber Karl. (1985). Pengetahuan Bahan dalam Pengerjaan Logam. Alih Bahasa: Harjapamekas Eddy D. Diplom Ing. Angkasa. Bandung.

Surawan, T., \& Mulyadi, D. (2019). Pengaruh Waktu pembebanan dan kecepatan terhadap keausan paduan tembaga $(\mathrm{Cu})$ dan karbon $(\mathrm{C})$. Jurnal Teknologi, 6, 71-84.

Tan L. H. (2019). Gas Welding. Akademi Teknik Mesin Industri (ATMI). Surakarta.

UU NO 23 Tentang Perkeretaapian. (2007). UU No. 23 Tahun 2007 tentang Perkeretaapian. In Lembaran Negara RI Tahun (Issue 23).

Manurung, V. A., Wibowo, Y. T. J., \& Baskoro, S. Y. (2020). Panduan Metalografi. Jakarta, Indonesia: LP2M Politeknik Manufaktur Astra.

Wanaradi, A. (2020). Desain Dan Rancang Bangun Prototype Surface Treatment Untuk Meningkatkan Ketahanan Permukaan Rel Kereta Api. Tugas Akhir. Madiun: Politeknik Perkeretaapian Indonesia.

Wirawan, W. A., Wahjono, H. B., \& Rozaq, F. (2020). Desain Prototype Teknologi Automatic Surface Treatmen Untuk Meningkatkan Ketahanan Jalan Rel Kereta Api. Jurnal Perkeretaapian Indonesia (Indonesian Railway Journal. https://doi.org/10.37367/jpi.v4i1.98

W.A. Wirawan, A. Aghastya, A. L. Lailya. (2019). Modeling Of Atmega 2560 MicrocontrollerBased Train Passenger Counter. Jurnal Perkeretaapian Indonesia. Vol. 3, No. 1, 2019. Hal 55-61. 
W.A. Wirawan, Tumiran Anang Cundoko, Hari Boedi Wahjono, Fadli Rozaq. Rancang Bangun Teknologi Automatic Surface Treatmen Untuk Meningkatkan Ketahanan Jalan Rel Kereta Api. Jurnal Perkeretaapian Indonesia (Indonesian Railway Journal), Vol. 5, No. 1, 2021. Hal. 1-9. DOI: https://doi.org/10.37367/jpi.v5i1.129 